\title{
Neuropsychological Functions in Short- and Long-term Alcohol Abstinence
}

\author{
Rajmohan Velayudhan ${ }^{1}$, Suni M Saraswathy ${ }^{2}$
}

\begin{abstract}
Background: Evidence suggests significant impairment across multiple cognitive functions and remains stable during the first few months of abstinence from alcohol and abates by one year. Methodology: The study was conducted in a tertiary care teaching hospital on 20 alcoholdependent patients each in the short- (STA) and long-term abstinence (LTA) group. Both the groups compared were age and sex matched. The Mini International Neuropsychiatric Interview (MINI) screening was used to diagnose alcohol dependence. The following neuropsychological tests were done to assess the case and control groups: Trail making test, verbal working memory: N-back test, Rey's auditory verbal learning test. Parametric and nonparametric test were used to analyze the data based on the criterion.

Results: There was no significant difference between STA and LTA groups in mean time taken to complete the task in Trail A and Trail B ( $t=1.16$, $p=0.25$ and $t=0.72, p=0.48$ ). There is no significant difference between two groups in working memory functions in verbal 2-back and 1-back errors or hits. There is a significant difference between long-term and short-term alcohol abstinent groups in immediate recall $(t=-2.189$, $p=0.03)$. There is no significant difference between two groups in other trials of learning and memory tasks.

Conclusion: The result of this study shows that there is no significant difference between short-term and long-term abstinent groups in attention, working memory task, verbal learning, and memory task. Longer duration of abstinence is required for the improvement in neuropsychological deficits due to alcohol use.

Keywords: Abstinence, Alcohol dependence, Executive dysfunction, Immediate recall.

Indian Journal of Private Psychiatry (2020): 10.5005/jp-journals-10067-0054
\end{abstract}

\section{INTRODUCTION}

Alcohol-use disorders mimic and exacerbate a wide range of medical and psychiatric conditions and thereby shorten the life span of affected people by more than a decade. Alcoholism's effects on the brain are diverse and are influenced by a wide range of variables. Although alcoholics have diffuse damage in the cerebral cortex of both hemispheres of the brain, neuropathological studies performed on the brains of deceased patients as well as findings derived from neuroimaging point to increased susceptibility of frontal brain systems to alcoholism-related damage. ${ }^{1}$

Neuroimaging techniques studied the blood flow and metabolism of the frontal lobe and found that chronic alcoholics will have decreased metabolism in the frontal lobes and this is correlated with impaired neuropsychological performance. ${ }^{2}$ Tedstone and Coyle investigated performance on neuropsychological tasks and tasks measuring different aspects of attention in a representative sample of sober alcoholics. In comparison with a nonalcoholic control group, the alcoholics were significantly impaired on all neuropsychological tasks and specific deficits in attention such as divided attention task. ${ }^{3}$ Neuropsychological performance in apparently cognitively, mentally, and physically healthy abstinent alcohol-dependent subjects compared with controls showed that the severity of dependence and length of abstinence was not associated with the performance of any task. ${ }^{4}$ A study has to evaluate the frequency of measurable dysfunction in hippocampus (HC)-related functional tests and its predictive value for risk to show that more than $50 \%$ of exhibited improvement in distinct $\mathrm{HC}$ dysfunction after 2 years. The study concluded that a slow but remarkable regeneration of $\mathrm{HC}$ functions occurs upon strict abstention from alcohol. ${ }^{5}$

\footnotetext{
1,2Department of Psychiatry, MES Medical College, Perinthalmanna, Kerala, India
}

Corresponding Author: Rajmohan Velayudhan, Department of Psychiatry, MES Medical College, Perinthalmanna, Kerala, India, Phone: +91 9895318590, e-mail: rajmohan.velayudhan@gmail.com

How to cite this article: Velayudhan R, Suni MS. Neuropsychological Functions in Short- and Long-term Alcohol Abstinence. Ind J Priv Psychiatry 2020;14(1):26-29.

Source of support: Nil

Conflict of interest: None

A comparison of cognitive functioning in alcoholics in various treatment phases including postdetoxification and years after abstinence showed that the residual deficits persist for years after detoxification in some patients. The most severe deficits have been observed in visuospatial abilities, perceptual-motor integration, abstract reasoning, and new learning. The most significant predictors of cognitive dysfunction in persons recovering from alcoholism are the time elapsed since the last drink and the person's age. The pattern and duration of a patient's alcohol abuse are relatively weak determinants of neuropsychological impairment during abstinence. ${ }^{6}$ A comparison of the cognitive function of alcohol dependent with that of controls at baseline and followed up after 18 months showed that cognitive performance of subjects was substantially lower than normative samples, with a third or more at or below the 10th percentile on performance averaged across all measures. ${ }^{7}$ A study conducted to examine the cognitive functioning of long-term abstinence showed that over the 6-month interval, the abstainers' episodic memory and

(-) The Author(s). 2020 Open Access This article is distributed under the terms of the Creative Commons Attribution 4.0 International License (https://creativecommons. org/licenses/by-nc/4.0/), which permits unrestricted use, distribution, and non-commercial reproduction in any medium, provided you give appropriate credit to the original author(s) and the source, provide a link to the Creative Commons license, and indicate if changes were made. The Creative Commons Public Domain Dedication waiver (http://creativecommons.org/publicdomain/zero/1.0/) applies to the data made available in this article, unless otherwise stated. 
executive performances had returned to normal, whereas the relapsers performed lower than before in the flexibility task and concluded that there was no significant difference regarding neuropsychological scores at baseline between abstainers and relapses. $^{8}$

Findings from the meta-analysis of 62 studies done that assessed cognitive dysfunctions among alcoholics revealed moderate impairment across 11 cognitive domains during short-term abstinence, with moderate impairment across 10 domains during intermediate-term abstinence. Small effect size estimates were found for long-term abstinence. These results suggest that significant impairment across multiple cognitive functions remains stable during the first year of abstinence from alcohol and abates by one year of sobriety. ${ }^{8}$

The present study assesses the neuropsychological functions of alcoholics in the early phase of abstinence (short-term) and compares it with the neuropsychologic functions of an age and sex-matched group who are abstinent for at least 1 year (long term).

\section{Materials and Methods}

The study was conducted in a tertiary care teaching hospital on 20 alcohol-dependent patients each in the short- and long-term abstinence group. Both the groups compared were age and sex matched. Long-term abstinent (LTA) was defined as abstinence from alcohol for 12 months and above while short-term abstinent (STA) was defined as abstinence for a period of 1 to 2 months. Both the groups are selected from the tertiary prevention clinic's alcoholic anonymous groups. They were included in the study after written informed consent based on the following criteria: patients meeting the definition for short- and long-term abstinence, age between 25 and 50 years, ability to read/write English and mother tongue (Malayalam), and a mini-mental status examination score above 23. Patients with a longitudinal or cross-sectional diagnosis of any other Axis I disorder or intellectual impairment, patients with a significant history of head trauma or cranial surgery or significant neurological disease including epilepsy or history of diabetes mellitus, hypertension, cardiovascular and coronary heart disease, and terminal illnesses were excluded. The subjects were postinclusion assessed using a sociodemographic questionnaire to obtain relevant data. The Mini International Neuropsychiatric Interview (MINI) screening ${ }^{9}$ was used to diagnose alcohol dependence and excludes other Axis I diagnosis. The mini-mental status examination (MMSE) was also administered. The following neuropsychological tests were done to assess the case and control groups: trail making test, verbal working memory: N-back test, Rey's auditory verbal learning test.

\section{Trail Making Test (TMT)}

It is used as a test of attention and visuomotor tracking. Adult version is 15 to 89 years. The tool was constructed in 1938 as "Partington's Pathways" or the "divided attention test" and was later adopted by Reitan in 1955. Reliability coefficients in clinical population are 0.69 to 0.94 for Part A, 0.66 to 0.86 for Part B. ${ }^{10}$

\section{Verbal Working Memory-N-back Task}

For the present study, 1-back and 2-back versions of the n-back test are used. The 1-back version requires verbal storage and rehearsal, while the 2-back version requires, in addition of above, manipulation of the information. Therefore, 1-back version involves the articulatory loop in the verbal modality and 2-back version involves the central executive. The number of hits and errors form the score in each test. The total number of omissions and commissions form the errors. Omissions are defined as the number of repetitions that are missed. Commissions are the number of nonrepetitions wrongly identified as repetitions. ${ }^{11}$

\section{Rey's Auditory Verbal Learning Test (RAVLT)}

Rey's auditory verbal learning test (AVLT) is adopted for different cultures. There are two lists A and B with 15 different words in each list. Word in list $A$ is presented at the rate of one word per second during 5 successive trials. After the completion of the 5 trials of list A, words in list $B$ are presented once and an immediate recall is taken for the same. Presentation of list B serves as interference and prevents the subject from recalling the words from list $A$ subsequently from immediate memory. This is followed by the immediate recall of words from list A. After a delay of 20 minutes, words in list $A$ are again recalled to form the delayed recall scores. Following the delayed recall, recognition of the word in list $A$ is tested. The words are called out one at a time and subjects indicate whether each word belonged to list $A$ or not. Hits and errors are recorded. ${ }^{12}$

\section{Procedure}

Institutional ethics committee clearance was taken prior to initiating the study. Specific appointment time was fixed for conducting the assessment. The assessment was done in therapy room in psychiatry department after getting the consent for the study. For short-term abstinence, patients who were continued in de-addiction treatment following detoxification were selected. For long-term abstinent group, alcoholic anonymous (AA) groups in the study area were contacted and detailed history was collected for understanding the level of abstinence. Thereafter, MINI screening for other psychiatric conditions and MMSE were administered.

Neuropsychological assessment was conducted in a specific order starting with trail making test (TMT). Rey's auditory verbal learning test (AVLT) was administered following it. In the 20-minute delay period for delayed recall of AVLT, verbal $n$-back test was administered. The assessments were completed with delayed recall task of (AVLT). Over all 45 minutes to 1 hour were taken to complete the assessment depending upon the patient.

Parametric and nonparametric tests were used to analyze the data based on the criterion. All tests were done using the Statistical Package for the Social Services version 16 (SPSS 16).

\section{Results}

Total sample sizes consist of 20 patients with short-term abstinence (STA) and 20 patients with long-term abstinent (LTA). The sociodemographic variables between the two groups are summarized (Table 1).

There is no significant difference in terms of age between $(t=-0.87$ and $p=0.57$ ) between long-term and short-term alcohol abstinence groups indicting that are homogeneous in nature. The duration of the alcohol use also showed no significant difference between the groups ( $t=-0.371$ and $p=0.14$ ). $65 \%$ in the STA group and the 55\% LTA group took de-addiction treatment once. In the STA group, the percentage of the patients who took treatment twice and thrice were 10 and $25 \%$, respectively. In the LTA group, it was 30 and 10, respectively, for 2 and 3 de-addiction treatments. 
Table 1: Sociodemographic characteristics of the study population

\begin{tabular}{|c|c|c|}
\hline & $\begin{array}{l}\text { Short-term } \\
\text { abstinence } \\
(S T A)(n=20)\end{array}$ & $\begin{array}{l}\text { Long-term } \\
\text { abstinence } \\
(\text { LTA })(n=20)\end{array}$ \\
\hline Age & $36.75(5.48)$ & $38.10(4.32)$ \\
\hline $\begin{array}{l}\text { Education } \\
\text { SSLC/10th } \\
\text { Higher secondary } \\
\text { Graduation } \\
\text { Postgraduation }\end{array}$ & $\begin{array}{l}5(25) \\
6(30) \\
7(35) \\
2(10)\end{array}$ & $\begin{array}{l}3(15) \\
3(15) \\
9(45) \\
5(25)\end{array}$ \\
\hline $\begin{array}{l}\text { Occupation } \\
\text { Unskilled } \\
\text { Semiskilled } \\
\text { Skilled }\end{array}$ & $\begin{array}{l}7(35) \\
7(35) \\
6(10)\end{array}$ & $\begin{array}{c}1(5) \\
12(60) \\
7(35)\end{array}$ \\
\hline $\begin{array}{l}\text { Income } \\
\text { Below 10,000 INR } \\
\text { 10,000-25,000 INR } \\
\text { Above } 25,000 \text { INR }\end{array}$ & $\begin{array}{r}4(20) \\
5(25) \\
11(55)\end{array}$ & $\begin{array}{r}5(25) \\
3(15) \\
12(60)\end{array}$ \\
\hline $\begin{array}{l}\text { Marital status } \\
\text { Single } \\
\text { Married } \\
\text { Separated } \\
\text { Widowed } \\
\text { Divorced }\end{array}$ & $\begin{array}{r}5(25) \\
11(55) \\
2(10) \\
1(5) \\
1(5)\end{array}$ & $\begin{array}{l}1(5) \\
16(80) \\
2(10) \\
0 \\
1(5)\end{array}$ \\
\hline $\begin{array}{l}\text { Religion } \\
\text { Hindu } \\
\text { Muslim } \\
\text { Christian } \\
\text { Others }\end{array}$ & $\begin{array}{l}15(75) \\
2(10) \\
3(15) \\
-\end{array}$ & $\begin{array}{l}16(80) \\
3(15) \\
1(5) \\
-\end{array}$ \\
\hline $\begin{array}{l}\text { Domicile } \\
\text { Rural } \\
\text { Suburban } \\
\text { Urban }\end{array}$ & $\begin{array}{r}2(10) \\
4(20) \\
14(70)\end{array}$ & $\begin{array}{l}- \\
8(95) \\
12(5)\end{array}$ \\
\hline $\begin{array}{l}\text { Family type }(n) \\
\text { Nuclear } \\
\text { Joint }\end{array}$ & $\begin{array}{r}15(75) \\
5(25)\end{array}$ & $\begin{array}{c}19(95) \\
1(5)\end{array}$ \\
\hline Duration of alcohol use (years) & $15.75(6.27)$ & $16.50(6.50)$ \\
\hline $\begin{array}{l}\text { Number of treatment } \\
1 \\
2 \\
3 \\
4\end{array}$ & $\begin{array}{l}13(65) \\
2(10) \\
5(25) \\
-\end{array}$ & $\begin{array}{l}11(55) \\
6(30) \\
2(10) \\
1(5)\end{array}$ \\
\hline
\end{tabular}

There was no significant difference between STA and LTA groups in mean time taken to complete the task in Trail $A$ and Trail $\mathrm{B}(t=1.16, p=0.25$ and $t=0.72, p=0.48)$ (Table 2). There is no significant difference between the two groups in working memory functions in verbal 2-back and 1-back errors or hits (Table 3).

There is a significant difference between long-term and shortterm alcohol abstinent groups in immediate recall $(t=-2.189$, $p=0.03$ ) (Table 4). There is no significant difference between the two groups in other trials of learning and memory tasks.

\section{Discussion}

Alcohol dependence is characterized by a neuropsychological profile of mild-to-moderate impairment. Recovery from alcoholism is associated with a partial reversal of CNS deficits that occur in
Table 2: Time trail making test (TMT) in short-term and long-term abstinent groups

\begin{tabular}{lllll}
\hline & & & \multicolumn{2}{c}{ Statistical analysis } \\
\cline { 4 - 5 } & $\operatorname{STA}(n=20)$ & $\operatorname{LTA}(n=20)$ & $t$ & $p$ \\
\hline Attention & & & & \\
TMT-A & & & & \\
$\begin{array}{l}\text { Response time } \\
\text { (seconds) }\end{array}$ & $54.05(21.41)$ & $47.10(16.06)$ & 1.161 & 0.253 \\
$\begin{array}{l}\text { TMT-B } \\
\text { Response time } \\
\text { (seconds) }\end{array}$ & $87.40(31.38)$ & $80.45(29.79)$ & 0.718 & 0.477 \\
\hline
\end{tabular}

Table 3:Working memory tasks in short-term and long-term abstinence

\begin{tabular}{lllll}
\hline & & & \multicolumn{2}{c}{ Statistical analysis } \\
\cline { 5 - 6 } Working memory & $\operatorname{STA}(n=20)$ & $\operatorname{LTA}(n=20)$ & $t / U$ & $p$ \\
\hline Verbal $n$-back & & & & \\
1-back hits & $8.80(0.41)$ & $8.85(0.49)$ & -0.350 & 0.728 \\
1-back errors^ & $0.65(0.82)$ & $0.25(0.64)$ & 193.00 & 0.127 \\
2-back hits & $5.70(1.56)$ & $5.30(1.30)$ & 0.881 & 0.384 \\
2-back errors & $5.35(2.99)$ & 2.00 & 0.807 & 0.425 \\
\hline
\end{tabular}

$\wedge$, nonparametric statistics

Table 4: Learning and memory task in short-term and long-term abstinence

\begin{tabular}{|c|c|c|c|c|}
\hline & \multirow[b]{2}{*}{$\operatorname{STA}(n=20)$} & \multirow[b]{2}{*}{$\operatorname{LTA}(n=20)$} & \multicolumn{2}{|c|}{ Statistical analysis } \\
\hline & & & $t / U$ & $p$ \\
\hline \multicolumn{5}{|l|}{$\begin{array}{l}\text { Verbal learning } \\
\text { and memory }\end{array}$} \\
\hline \multicolumn{5}{|l|}{ AVLT } \\
\hline Trial 1 & $6.00(0.81)$ & $6.40(1.23)$ & -0.818 & 0.418 \\
\hline Trial 2 & $8.00(2.05)$ & $8.40(1.27)$ & 180 & 0.602 \\
\hline Trial 3 & $10.40(2.50)$ & $10.30(2.32)$ & 0.131 & 0.896 \\
\hline Trial 4 & $12.20(2.09)$ & $11.85(2.16)$ & 0.521 & 0.606 \\
\hline Trial 5 & $12.50(1.93)$ & $12.45(2.14)$ & 0.078 & 0.939 \\
\hline Total trials & $49.10(9.41)$ & $49.40(7.75)$ & -0.110 & 0.913 \\
\hline Trial B & $6.75(1.74)$ & $6.30(1.56)$ & 0.860 & 0.395 \\
\hline Immediate recall & $8.45(2.23)$ & $9.90(1.94)$ & -2.189 & $0.035^{*}$ \\
\hline Delayed recall & $6.90(2.49)$ & $8.05(2.26)$ & -1.530 & 0.134 \\
\hline $\begin{array}{l}\text { Long-term percent } \\
\text { retention }\end{array}$ & $54.71(16.19)$ & $65.79(18.72)$ & -2.001 & 0.053 \\
\hline Recognition & $12.65(3.06)$ & $13.70(1.976)$ & -1.287 & 0.206 \\
\hline
\end{tabular}

${ }^{*} p<0.05$ 
alcoholism. The reversal of deficits during recovery from alcoholism indicates that brain structure is capable of repair and restructuring in response to insult in adulthood. Indirect support of this repair model derives from studies of selective neuropsychological processes, structural and functional neuroimaging studies, and preclinical studies on degeneration and regeneration during the development of alcohol dependence and recovery form dependence. $^{13}$

In the present study, there is no significant difference between long-term and short-term abstinence in TMT A and TMT B scores. This result is similar to the findings for a previous study by Tedstone and Coyle. ${ }^{3}$ This study also is in concordance with another study that compared the cognitive function of alcohol-dependent with that of controls which showed that deficit in executive function and attention deficit were continued even after 18 months in that study. $^{14}$

Working memory, a concept put forth by Baddeley, refers to the capacity to hold and manipulate information for ongoing processes. ${ }^{12}$ This capacity is required to integrate the information with long-term memory and with other information being processed either serially or parallel. In the present study also, there is no significant difference between the means of both verbal n-back. This shows that the working memory deficits may need longer period to recover or the damage may be irreversible (Table 3). Learning and memory are the capacities by which a person is able to gain experience and retain it. Learning is the means of acquisition of new information about the environment, and memory is the process of retaining it. Rey's auditory verbal learning test (AVLT) was used in the present study to measure verbal learning and memory. In the present study, there is significant difference between two groups in the immediate recall task of verbal learning; this shows that learning capacity recovers faster for abstainers (Table 4). In delayed recall scores, there is no significant difference between the two groups in the present study.

This echoed the results of a study by Bartels and colleagues to evaluate the frequency of measurable dysfunction in hippocampus (Hc)-related functions and showed that more than $50 \%$ exhibited distinct $\mathrm{HC}$ dysfunction at inclusion that returned to normal after 2 years. Study concluded slow but remarkable regeneration of HC functions upon strict abstention from alcohol. ${ }^{5}$ The present study is in concordance with the findings of the meta-analysis by Stavro and colleagues and revealed moderate impairment across 11 cognitive domains during short-term abstinence, with moderate impairment across 10 domains during intermediate-term abstinence. Generally, dysfunction abates by 1 year of sobriety. ${ }^{15}$ These findings support the diffuse brain hypothesis and suggest that cognitive dysfunction may linger for up to an average of 1-year postdetoxification from alcohol.

The result of this study shows that there is no significant difference between short-term and long-term abstinent in attention, working memory task, verbal learning, and memory task. Longer duration of abstinence is therefore needed for the improvement in neuropsychological deficits due to alcohol use.

This study is restricted by small sample size, and cross-sectional design, even though matched group sample has selected for the study. Large sample with multiple sites of sample collection and cohort study with nonalcoholic controls has to be taken into consideration and assesses the type of treatment as well as number of relapse to consider. Treatment implication of the study includes a consideration of neuropsychological assessment and rehabilitation since this will help to reduce relapse.

\section{References}

1. Moselhy HF, Georgiou G, Kahn A. Frontal lobe changes in alcoholism: a review of the literature. Alcohol Alcohol 2001;36(5):357-368. DOI: 10.1093/alcalc/36.5.357.

2. Adams KM, Gilman S, Johnson-Greene $D$, et al. The significance of family history status in relation to neuropsychological test performance and cerebral glucose metabolism studied with positron emission tomography in older alcoholic patients. Alcohol Clin Exp Res 1998;22(1):105-110.

3. Tedstone D, Coyle K. Cognitive impairments in sober alcoholics: performance on selective and divided attention tasks. Drug Alcohol Depend 2004;75(3):277-286. DOI: 10.1016/j.drugalcdep.2004. 03.005.

4. Davies SJ, Pandit SA, Feeney A. Is there cognitive impairment in clinically 'healthy' abstinent alcohol dependence? Alcohol Alcohol 2005;40(6):498-503. DOI: 10.1093/alcalc/agh203.

5. Bartels C, Kunert HJ, Stawicki S, et al. Recovery of hippocampusrelated functions in chronic alcoholics during monitored long-term abstinence. Alcohol Alcohol 2007;42(2):92-102. DOI: 10.1093/alcalc/ agl104.

6. Fein G, Bachman L, Fisher S. Cognitive impairments in abstinent alcoholics. West J Med1990;152(5):531-537.

7. Bates ME, Bowden SC, Barry D. Neurocognitive impairment associated with alcohol use disorders: implications for treatment. Exp Clin Psychopharmacol 2002;10(3):193-212. DOI: 10.1037//10641297.10.3.193.

8. Pitel AL, BeaunieuxH, Witkowski T. Genuine episodic memory deficits and executive dysfunctions in alcoholic subjects early in abstinence. Alcohol Clin Exp Res 2007;31(7):1169-1178. DOI: 10.1111/j.15300277.2007.00418.x.

9. Sheehan DV, Lecrubier Y, Harnett-Sheehan K, et al. The Mini-International Neuropsychiatric Interview (M.I.N.I.): the development and validation of a structured diagnostic psychiatric interview for DSM-IV and ICD-10. J. Clin Psychiatry 1998;59(suppl 20): 22-33.

10. Reitan RM. The relation of the trail making test to organic brain damage. J Consult Psychol 1955 Oct;19(5):393-394. DOI: 10.1037/ h0044509.

11. Smith $\mathrm{EE}$, Jonides J. Working memory: a view from neuroimaging Cogn Psychol 1997;33(1):5-42. DOI: 10.1006/cogp.1997.0658.

12. Maj M, Satz P, Janssen R, et al. WHO Neuropsychiatric AIDS Study, cross-sectional phase II. Neuropsychological and neurological findings. Arch Gen Psychiatry 1994;51(1):51-61. DOI: 10.1001/ archpsyc.1994.03950010051007.

13. Crews FT, Buckley T, Dodd PR, et al. Alcoholic neurobiology: changes in dependence and recovery. Alcohol Clin Exp Res 2005;29(8):1505-1513. DOI: 10.1097/01.alc.0000175013.50644.61.

14. Baddeley A. Working memory: looking back and looking forward. Nat Rev Neurosci 2003;4(10):829-839. DOI: 10.1038/nrn1201.

15. Stavro K, Pelletier J, Potvin S. Widespread and sustained cognitive deficits in alcoholism: a meta-analysis. Addict Biol 2013;18(2):203-213. DOI: 10.1111/j.1369-1600.2011.00418.x. 